\title{
TEORÍA Y PRÁCTICA
}

\section{CUANDO ÉRAMOS EMIGRANTES (2) RELACIONES SOCIALES}

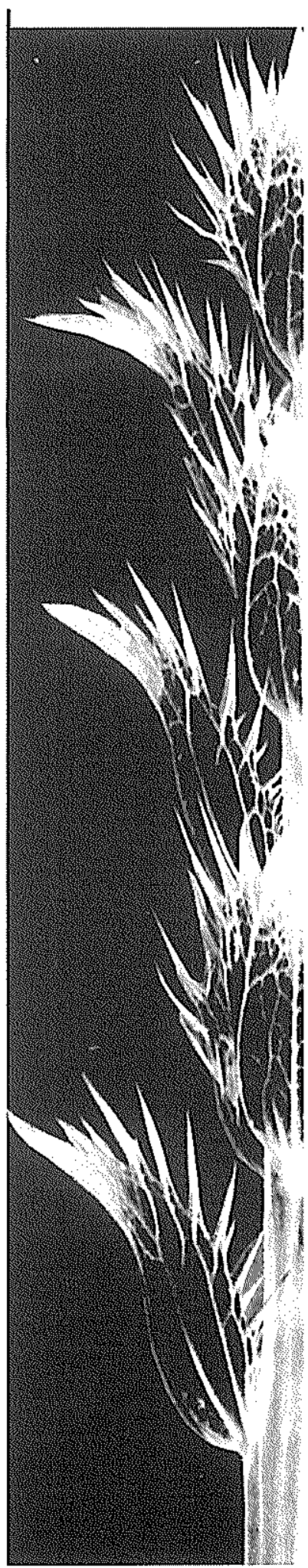

n el presente artículo, segunda parte de la serie "Cuando éramos emigrantes", expongo cómo ha sido la evolución laboral y social de los emigrantes españoles de primera genera-

\section{Francisca Ruiz Garzón Dpto. de Antropolocía Social Universidad de Granada}

ción desde que llegaron al pais extranjero hasta hoy. Experiencias tenidas en las empresas de trabajo, puestos que han ocupado, trato con sus compañeros autóctonos, etcétera. Por otro lado, la situación vivida a su alrededor, relaciones con otros españoles, relaciones con los vecinos, cómo ha sido y cómo es el dominio del idioma, junto a los problemas que se han tenido debido a la dificultad de éste.

\section{LA FABRICA}

Durante los años sesenta se da una gran demanda de mano de obra en el mercado internacional de trabajo, y, al mismo tiempo, una desbordante oferta de trabajadores en paro en los países mediterráneos, España entre ellos.

Para los emigrantes no fue fácil la llegada al país extranjero, aunque la tranquilidad les llegaría una vez resuelto todo el "papeleo" necesario, ya que, obtenido el permiso de residencia, el de trabajo y solucionado el problema de alojamiento, su permanencia en Alemania estaba regulada y podian incorporarse al trabajo.

Durante los primeros diez a quince años de emigración, el estado alemán aprovechó una mano de obra joven y barata. La mayoria de los españoles ocupaban los lugares más bajos de la escala laboral alemana, debido a la escasa cualificación obtenida antes de emigrar. (Comisión Episcopal de Migraciones 1981)

La mayoría de los puestos de trabajo eran para los

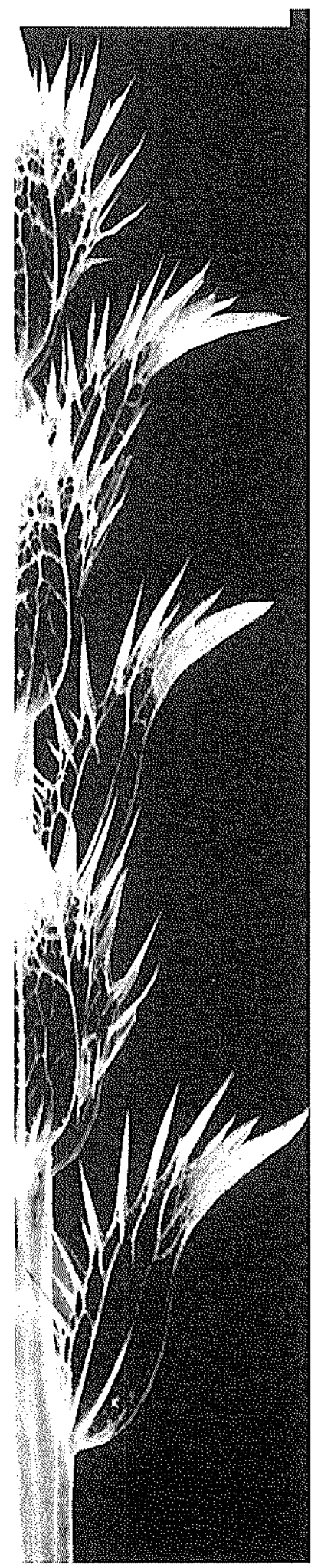


sectores de obras públicas, mineria, construcción y agricultura; campos laborales que no tenían alicientes para los trabajadores nacionales y que podian permitirse rechazar.

Los entrevistados han tenido una gran dificultad desde el punto de vista intelectual y humano de adaptarse a un medio, no sólo sociocultural, sino también laboral. Se ha pasado del trabajo en el campo, donde sólo se manejaban las manos y un tractor, a tener que manejar las sofisticadas máquinas de la industria alemana. Cuando los trabajadores entraban en las empresas, se les hacian contratos de seis meses de prueba, durante los cuales tenian que demostrar que eran aptos para cubrir los puestos.

Para unos hubo una fase previa de aprendizaje del funcionamiento de las maquinarias, otros tuvieron que aprender sobre la marcha la labor que debian ejecutar. En cambio, otros trabajadores, principalmente los que trabajaban en los astilleros, tuvieron la oportunidad de asistir a cursos de perfección en el oficio. Al cabo de otros seis meses, el contrato laboral pasaba a ser indefinido. Los españoles siempre han gozado de buen prestigio en los trabajos; se les consideraba gente trabajadora y formal.

Con el paso del tiempo, los españoles que se han asentado en el país de emigración han podido tener la oportunidad de acceder a nuevos puestos de trabajo, mejor remunerados, dentro de la cualificación que tenían o que han ido adquiriendo con los años. Ello se une con la mejora o el perfeccionamiento del nuevo idioma:

"Me vine con un contrato de trabajo en una fábrica de medicina, en un pueblo de aqui cerca de Ütersen. A treinta kilómetros. Alli estuve dos años y luego me vine a Hamburgo y empecé a trabajar en el Banco Español-Alemán, que era una sucursal del Banco Exterior de España, y después de cinco años de estar en aquel banco me fui a un banco alemán y es donde ahora trabajo, que es una filial del Dresdner Bank" [Pedro Mata $1^{2}$ generación 2000].

Es asi como se pasa a una etapa de mayor estabilidad económica y laboral, aunque algunos permane- cen en la misma empresa que les contrató cuando llegaron de España. Estos pocos que se han quedado y han permanecido en la misma empresa de llegada, son los que ya se piensan quedar definitivamente en Alemania o esperar para la jubilación si la empresa no quiebra antes:

"Soy licenciada en Matemáticas y desde que llegué de España hace treinta años trabajo en una empresa multinacional de programación en la que ya mismo me jubilo" [Antonia $1^{2}$ generación 2000].

Otros prueban suerte en diversos trabajos como pequeños empresarios autónomos. Podemos encontrar en la ciudad de Hamburgo gran cantidad de pequeños negocios familiares dirigidos por españoles: restaurantes, tiendas de comestibles, etc., donde el exotismo de "made in Spain" es lo que se vende:

"Estuvimos trabajando de aqui para allá y de aqui no he salido. Aqui estuve trabajando en varias empresas, en la construcción, en el metro, y en el 74 que ya habian nacido mis dos hijos (un hijo y una hija), me hice con el restaurante. En aquella época no habia problema de trabajo. Al principio habia muchos griegos autónomos, con restaurantes etc. Lo que al español le ha faltado la cosa ésta de independizarse. $Y$ mi mujer, pues, estaba todo el tiempo por qué no montamos algo independientemente, $y$ al final, pues, tuve la oportunidad de conseguir este local que era antes una cervecería y lo hice en plan de restaurante, y con la ayuda de mi mujer pues lo montamos" [Pablo Aragón $1^{2}$ generación 2000].

Las mujeres han trabajado de limpieza doméstica contratadas por horas, debido a la necesidad de estar en casa para el cuidado de los hijos. Trabajaban principalmente en horarios en los que los niños estuvieran en el colegio o en horarios en los que algún miembro responsable de la familia estuviese en la casa. No eran sueldos muy altos, pero ayudaban a cubrir gastos de última hora:

"La mayoria de la mujeres han empezado en la industria a trabajar, limpiando o donde 


\section{TEORÍA Y PRÁCTICA}

sea porque la vida es cara aqui, los alquileres y todo para que trabaje uno solo, pues no puede ser. Algunas han procurado estar aseguradas en la industria y buscarse trabajitos de limpieza aparte, y las que no pueden trabajar en la industria, pues trabajan en la limpieza. Buscan desesperadamente trabajos donde se gane mucho y no se cotice, siempre que tengan alguno que cotice por el tema de las pensiones, pero que tampoco se preocupan demasiado por cotizar" [Agregado laboral del consulado español en Hamburgo 1999].

En otros casos, algunas familias cuentan que no les era rentable trabajar los dos miembros de la familia, ya que los impuestos que se debian pagar se llevaban una gran cuantía de las ganancias:

"Trabajé durante tres o cuatro años, pero no salia rentable trabajar. Mi marido trabaja por su cuenta, es autónomo y entonces aqui cuanto más ganas, más pagas al estado. Entonces no valia la pena, luego era mucho estrés también, la niña la tenia que tener en la guarderia, luego ir a recogerla, llevarla, la comida, la casa. Era mucho y llegó un momento que dije, ya no más" [Eva $1^{a}$ generación 2000].

Otras mujeres se dedicaron durante muchos años a ser amas de casa, hasta que los hijos ya eran suficientemente maduros como para quedarse solos en casa sin ningún problema:

"Mi mujer ella... era lo que en España se llamaba las labores propias de su sexo. Asi formulaba en los formularios. Labores propias de su sexo, es decir que estaban todo el dia pariendo. Ahora no, ahora pone labores o sus labores, incluso añadía... no trabaja ama de casa iqué cinismo! ¿Eh?" [Fernando $1^{2}$ generación 1999].

A pesar de la dureza de comenzar en un nuevo país a trabajar y a vivir, con un idioma desconocido para los emigrantes españoles, y con unas costumbres, hábitos y cultura totalmente distintos, la mayoria de los emigrantes españoles en Alemania afirman no haberse sentido mal en el trabajo, ni haber sido

rechazados por la condición de ser emigrante ni por ser español. El agregado laboral del Consulado Español en Hamburgo explicaba asi el tema de la marginación:

"Los españoles en

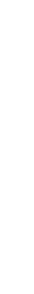



niños, nos fuimos a una vivienda ya grande" [Francisco $1^{a}$ generación 2000].

Pero ante todo para poder beneficiarse de cualquier ayuda, para conocer el funcionamiento de las instituciones alemanas, o poderse mover en aquella sociedad, era cuestión fundamental el manejo del idioma aunque fuese de la forma más rudimentaria posible.

\section{DOMINIO DEL IDIOMA ALEMÁN.}

Algunos emigrantes tuvieron suerte a su llegada al poderse encontrar con otros españoles que estaban en la misma situación de desorientación o que ya estaban más situados y conocían la existencia y el funcionamiento de algunas instituciones sociales. Pero otros muchos tuvieron unos comienzos dificiles al verse en un ambiente totalmente alemán y aislados de la población española. Esto para algunos tuvo sus ventajas y para otros sus inconvenientes:

\begin{abstract}
"Poco a poco aprendimos el idioma, luego con el contacto con gente alemana y el verte obligada a aprender el idioma, si no tienes gente española a tu alrededor, no te queda más remedio que aprender el alemán, pero, bueno, eso fue una experiencia muy positiva porque no tenias a nadie a quien preguntarle y asite lanzas, tienes que hacerlo sola. Tan pronto como tienes a gente a tu alrededor tiendes a agarrarte a esa persona" [Ana Mata $1^{2}$ generación 2000].
\end{abstract}

El nivel de conocimiento de la lengua alemana que los españoles emigrados han alcanzado es muy diverso. Dependiendo de una serie de factores, los emigrantes se vieron en la obligación de dominar más o menos el idioma. En el grupo de la primera generación, ha influido mucho en su aprendizaje del alemán el contacto que han tenido con el resto de la población española. Cuanto mayor haya sido el contacto con esta población española, menor es el nivel de vocabulario alemán aprendido. El tener hijos matriculados en las guarderias o en los colegios, forzaba a los padres a tener contacto con los profesores; a unos el tipo de trabajo que habian obtenido les forzaba a poder comprender y expresarse en el idioma, mientras que a otros no les exigian para su labor ningún tipo de nivel salvo la puntualidad y el rendimiento en el trabajo:

"Mi padre se cree que sabe hablar el alemán, pero no hay Dios que lo entienda, ni siquiera yo. Se sabe comunicar, si quiere ir a comprar a algún sitio, va y trae lo que tiene que traer, pero, sin embargo, no tiene ni idea. Mi madre sí. Mi madre se tuvo que arreglar más, tuvo que ir a comprar, tuvo que ir a la escuela con nosotros, tuvo que hacer todo, y fue aprendiendo más. Mi padre estuvo trabajando en una fábrica aqui en el puerto, le dijeron haz esto y 10 hizo, nada de hablar. Mi madre tuvo que comunicarse más y por eso tuvo que aprender mejor el alemán" [Miguel $2^{a}$ generación 2000]

El contacto con otros miembros de la población autóctona, conocer sus formas de vida, sus creencias y tradiciones llega a través del conocimiento de la lengua del país en el que se está. Durante los primeros años de estancia en el país extranjero, es evidente que el contacto con la población alemana no fuese muy frecuente, lo justo y necesario para hacerse entender. Sin embargo, a medida que van pasando los años, ya se tienen algunas destrezas en el manejo de la lengua. Esto nos muestra la nueva tendencia a tener un tipo de relaciones sociales y abandonar otras.

\section{CONTACTO CON LA POBLACIÓN ESPAÑOLA}

Durante los primeros años de emigración, la población española que no tenía contacto con otros españoles, por la gran distancia que los separaba, vivía de forma más aislada:

"Cuando nos vinimos a Alemania, era dificil porque estábamos en un ambiente alemán todo el tiempo porque estábamos incomunicados, no habia gente española. Pero desde que nos vinimos aqui a donde vivimos ahora, en el 88, pues estamos siempre donde están los españoles. Somos socios del Centro Gallego, vamos a la Misión Católica, vamos a misa española, o sea, que el contacto con españoles es mucho" [Piedad $1^{2}$ generación 2000].

. 
En estos primeros comienzos hubo gente que encontró apoyo en la población española y se crearon las primeras asociaciones, las asociaciones de padres; la comunidad española tenía algo que compartir y se necesitaban los unos a los otros, al estar todos en igualdad de condiciones y pasar por experiencias similares. La "morriña" de la tierra dejada atrás y los malos tragos pasados en el país extranjero (como cambios en los hábitos culinarios, formas de vida, etc) eran excusas perfectas para reunirse y "desahogarse" un poco. Sin embargo, en el fondo no eran excusas, sino necesidades reales de los emigrantes. Los recuerdos del pais de procedencia estaban en todo momento presentes en las familias españolas. Se celebraban reuniones donde se compartían los alimentos típicos del lugar de procedencia, donde, como me decían algunos de mis entrevistados, no faltaba "el vino con queso manchego, el jamón de jabugo y demás embutidos españoles, la música de la época," etc.

En el tiempo que dura la adaptación al nuevo pais, los emigrantes no tienen capacidad para preocuparse por la marcha social del nuevo estado en el que habitan. Sólo se preocupan de que no les falte el trabajo para dar de comer a la familia y poder ahorrar algo para el retorno. Cuando necesitaban un respiro, buscaban a sus semejantes, gente que entendiera y compartiese su cultura.

Cuando se pasa a una situación más estable, como por ejemplo por una mejor situación laboral, el comienzo de la escolarización de los hijos en el sistema alemán, una vivienda con comodidades, las familias proyectan un asentamiento a más largo plazo.

Los emigrantes españoles empiezan a interesarse por el estado alemán, por su funcionamiento, por el sistema burocrático, la política, etc. La comunidad española se da cuenta de que los cambios de carácter político repercuten sobre la situación social de la población migran. te, como es el caso de las ayudas sociales, los tipos de contratos, las ayudas por desempleo, etc. Es en este momento cuando los emigrantes pueden ser críticos con la sociedad del país de acogida y distinguir lo que les agrada de éste y lo que les desagrada:

"Me gusta de Alemania que hay mucha ayuda familiar, el sistema alemán me gusta mucho desde siempre, la organización alemana, la rapidez con la que se mueven las cosas burocráticas, judiciales... Me gusta el sistema laboral de aqui. La disciplina alemana, los jefes llegaban tan pronto o más que los trabajadores. Lo malo es que es una sociedad que permanece muy en si misma" [Familia Mata $1^{2}$ generación 2000].

Sin embargo el que conozcan más o menos el funcionamiento de la burocracia alemana no significa que tengan contacto directo con la población nati-

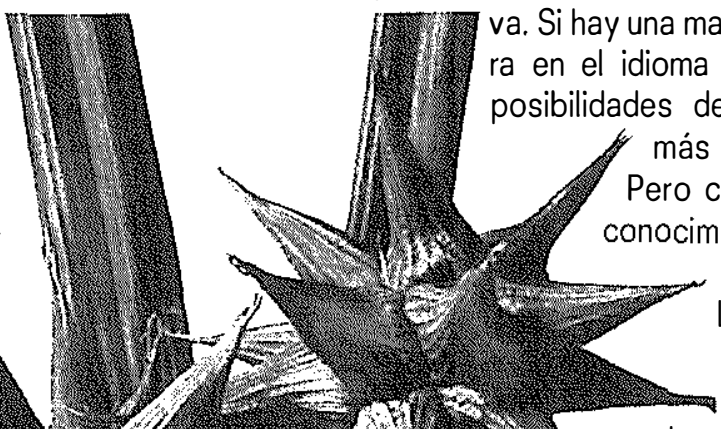
va. Si hay una mayor fluidez y soltura en el idioma alemán, hay más posibilidades de que se tengan cuando el nivel de cimiento del alemán es muy escaso, las relaciones se centran más en vecinos españoles o en el núcleo familiar.

En unos el interés por conocer a la población autóctona se despertaba más pronto que en otros, dependiendo, como muchos de mis entrevistados decian, "de cómo se den las circunstancias y la suerte que tengas en la vida..."

Las experiencias adquiridas en Alemania durante los primeros años de emigración marcarian definitivamente al emigrante. El haberlo "pasado mal" es una vivencia común a todos cuando llegaban por primera vez a un país extranjero en el que no se terminaban de situar. Sin embargo van a ser las malas experiencias vividas posteriormente

Carrizo, formas de los frutos.

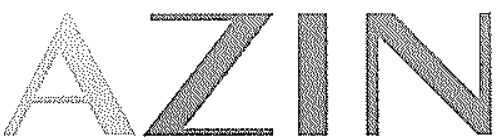


en el trabajo y en la vida diaria las que harán que el emigrante decida no aguantar más la situación y abandonar cuanto antes, o aislarse dentro de la comunidad española y permanecer reacio a cualquier relación con la población autóctona. Entre otros factores que influyen en estas malas experiencias, como pueden ser el dominio del idioma, que uno no se sepa defender en una discusión, etc. podriamos hablar del factor "suerte". Como decian mis entrevistados, influyen infinidad de factores para que a un emigrante le vayan bien las cosas o no: el barrio en el que viva, el trabajo, los compañeros, los jefes, el carácter de la persona, la propia autoestima, el apoyo que tenga de su familia, etc.

F.R.G.

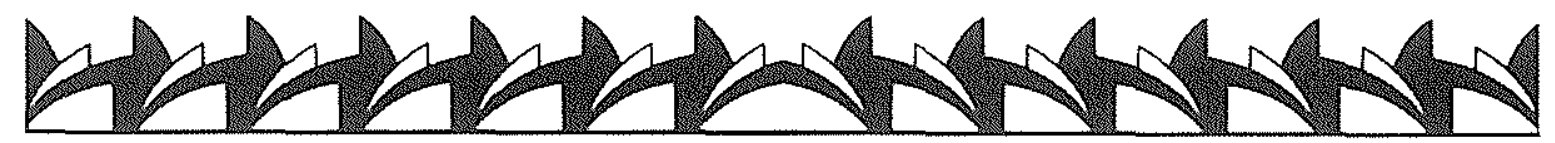

DeR HUNDETRAM

\section{Der Hundetraum}

die Uhr an der Wand. Mein Gott! Schon Waldemar sieht aut die Uhr an der Wanzen $\mathrm{Nach}$ mittag so fast sechs Uhr. Er hat schon den Anfang an keine Lust gehabt. langweilig gefunden. Er hat von An Hermann. Herbert und Kaffee und Kuchen bei Doris und Bruno und Beate sowieso. Sabine sind natürlich auch da. Und Brung und Und dann auch Diese Freunde von seiner Frau. noch Raimund, ihr Friseur.

Waldemar wollte zu Hause bleiben, auf dem Sofa liegen und Später vielleicht ein bisschen spazieren einfach nichts tun. Spa er nicht zu Doris und Hermann! gehen. Warum nicht? Aber Schätzchen", hat Linda um halb "Natürlich kommst du mit, Sch hicht alleine gehen lassen, drei gesagt, "du kannst mich doch niche so gute Torte. Die hat und bei Doris gibt es doch immer

dir doch immer geschmeckt." die gleiche Torte.

Oh Gott! Diese Torte. Immer die gein süßer Likör. Aprikose Schokoladentorte. Brrr! Und danach ein suß Den süßen Likör hat oder Himbere. Der ist noch schlimmer. Den sur er nie getrunken. weder zu Hase Das verspreche ich. Zwei Stundchen das Der Loonhard Thoma
und andere Verwirrumgen

\section{Lecturas en alemán}

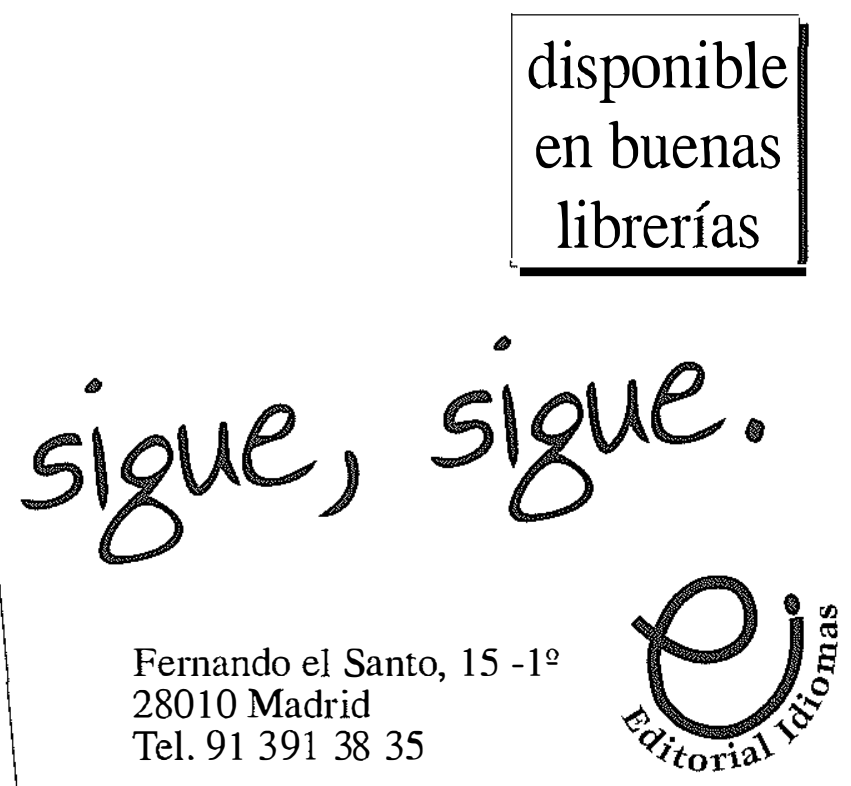

